\title{
Effect of HPAM on Calcium Carbonate Crystallization
}

\author{
Guolin Jing*, Shan Tang, and Xiaoxiao Li \\ Provincial Key Laboratory of Oil \& Gas Chemical Technology, College of Chemistry \& Chemical Engineering, \\ Northeast Petroleum University, Daqing, 163318, China.*E-mail: jingguolin@yahoo.cn
}

(Received February 26, 2013; Accepted March 18, 2013)

\begin{abstract}
With the wide application of ASP (alkaline-surfactant-polymer) flooding, the scaling becomes more and more serious, which is harmful to the oilfield and environment. In order to investigate the effects of HPAM on calcium carbonate crystallization, the crystallization behaviors of $\mathrm{CaCO}_{3}$ in HPAM (Hydrolyzed polyacrylamide) solutions were studied and the composition and morphology of $\mathrm{CaCO}_{3}$ crystal were investigated in different concentrations of polyacrylamide solutions. The crystal forms and morphologies of $\mathrm{CaCO}_{3}$ were characterized by Fourier transform infrared spectroscopy, X-ray diffraction and scanning electron microscopy. The results show that the crystallization of $\mathrm{CaCO}_{3}$ is strongly influenced by the HPAM. The paper analyzed the internal cause, and the results show: The reasons leading to the change of morphology are carboxyl groups in polyacrylamide molecule and $\mathrm{Ca}^{2+}$ in solution form chelates by coordination bond. And the chelates are adsorbed on the calcium hydroxide surfaces of solid-liquid interfaces so as to change the formation rate of calcium carbonate crystal nucleus. The research provides a reliable basis for the mechanism research of the scaling problem in the oil extraction process of ASP flooding and the adoption of scale inhibition and scale inhibitor.
\end{abstract}

Key words: HPAM, Calcium carbonate crystallization, Vaterite, Internal cause

\section{INTRODUCTION}

Formation of insoluble mineral salts from supersaturated aqueous electrolyte solution is an important and expensive problem in the several industrial processes such as hydrometallurgy, water desalination, enhanced oil recovery in petroleum industry etc. ${ }^{1,2}$ The mineral scales such as calcium carbonate can deposit at the surface of metals in the heat exchanges, boilers and petroleum production equipment etc. The scale can take place anywhere along the oil pipeline and processing facilities that leads to fouling and increasing turbulences and consequently, blocking the flow line. ${ }^{3,4}$

Among the barely soluble salts calcium carbonate is one of the most studied. Precipitation of calcium carbonate is a widely occurring process in nature and it is an important industrial product. ${ }^{5}$ Hence its precipitation is of particular interest not only for fundamental research concerning for biomineralization but also their importance in industrial applications..$^{6-13}$ Much of the discussion around scaling has been the formation of scale in the petroleum industry. Calcium carbonate crystallizes in three different anhydrous polymorphs. ${ }^{14-16}$ These are in order of increasing stability; vaterite, aragonite and calcite. ${ }^{17,18}$ Vaterite has a hexagonal structure that usually results in spherulites; aragonite has an orthorhombic structure, often found as needle-like particles, while calcite has a trigonal structure, shaped as cubes. The least stable polymorph has the highest solubility and will transform by dissolution and re-crystallization into a more stable modication over time. ${ }^{19}$ Vaterite and aragonite are thermodynamically unstable and can transform easily to calcite. ${ }^{20-24}$ The initial composition of different polymorphs is determined both by thermodynamics and kinetics. ${ }^{25,26}$

ASP (alkaline-surfactant-polymer) flooding technology, an important technology of tertiary oil extraction, has been found to enhance oil recovery by over $20 \%$, and it has been used in full-scale in Daqing oileld which is the most successful case of ASP flooding in the world. ${ }^{27}$ Therefore, the aim of the present study is to investigate the effect of HPAM (the polymer components in the ASP flooding) on the crystal structure of $\mathrm{CaCO}_{3}$ deposited. ${ }^{28-30}$ There is few studies have been carried out to study the effect of the HPAM on scale deposition and crystal growth. Thus, understanding the HPAM on crystallization and crystal growth at the surface is important for industrial applications.

In our experimental system, in order to investigate the effect of the HPAM on the crystal growth polymorphic phases of calcium carbonate, the systematic study of the growth of calcium carbonate in the presence of HPAM was analyzed by XRD and IR. The morphology and the structure of the crystallites were observed by scanning electron microscopy. 


\section{EXPERIMENTAL}

\section{Materials}

The DGG-9023A type of drying oven, electronic balance, constant temperature bath, cyclotron oscillator, Rigaku D/MAX-r type of rotating target X-ray diffractometer (Rigaku Corporation), V33 infrared spectrometer (the company of Germany BRUKER spectrometers), and HITACHI S-3400N type of scanning electron microscope (Hitachi, Japan) were adopted to investigate the effect of HPAM on calcium carbonate crystallization.

The chemical formula of HPAM is:<smiles>CC(CC(CCCCC(=O)O)C(N)=O)C(=O)O</smiles>

The anhydrous $\mathrm{CaCl}_{2}, \mathrm{NaHCO}_{3}$, EDTA, $\mathrm{KOH}, \mathrm{NaOH}$, and HPAM were adopted in the test, and all of the above agents were analytical pure agents.

\section{Assays for Calcium Ion}

This experiment investigates the influence on the concentration of calcium ion under different concentrations of HPAM in 60 centigrade, meanwhile, investigates the remaining concentration of calcium ion under the blank situation using distilled water instead of HPAM.

\section{Test Analysis}

The structure and morphology of $\mathrm{CaCO}_{3}$ were tested and analyzed by X-ray diffractometer and using scanning range of $5-80^{\circ}, \mathrm{V} 33$ infrared spectrometer, and scanning electron microscope.

\section{RESULTS AND DISCUSSION}

\section{The Influence of HPAM Concentration on Calcium Carbonate Formation}

The results were shown in Fig. 1 through measuring the concentration of calcium ion in the solution when added different concentration of HPAM. As observed from Fig. 1, the remaining concentration of calcium ion firstly increased, and then reduced with the increasing of concentration of HPAM reaches up to maximum at $300 \mathrm{ppm}$. The Fig. 1 showed that adding HPAM had a certain inhibitory action to the calcium carbonate scales formation and changed with the concentration changing. Microanalysis also found stable metastable crystal vaterite appeared in calcium carbonate crystal when 300 ppm HPAM added. Obviously, existing in the form of vaterite, Calcium carbonate crystals were

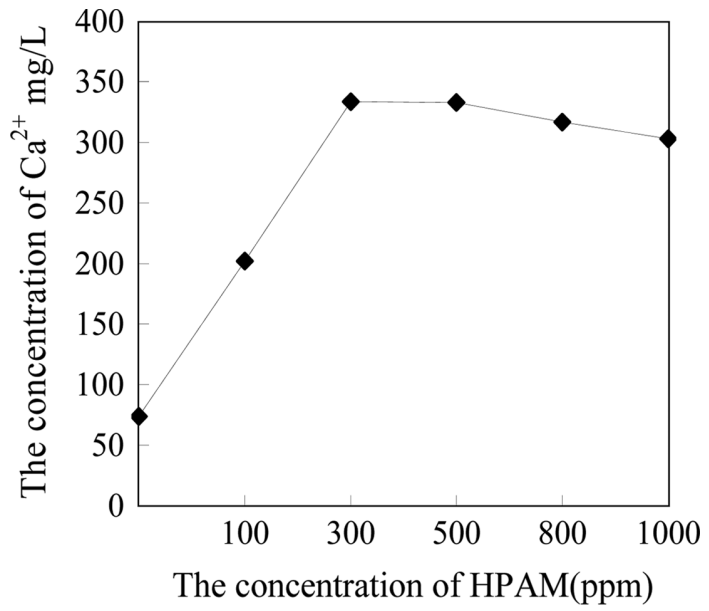

Figure 1. The concentration of calcium ion in the solution with HPAM in different concentration.

not easy to form scales.

The calcium carbonate crystal forms without polyacrylamide and under different conditions of polyacrylamide respectively were analyzed by X-ray diffraction, V33 infrared spectrometer and HITACHI S-3400 scanning electron microscope. In order to ensure the result reliabilities of XRD, IR and SEM, several diagrams with obvious phenomena were selected and analyzed in detail.

\section{XRD Analysis}

Fig. 2 to Fig. 5 are the X-ray diffraction diagrams of calcium carbonate samples under different conditions. Through the analyses of XRD diagrams above, it is indicated that the calcium carbonate crystal exists in the steady state of calcite when no HPAM is added in Fig. 2. Fig. 3 is the XRD diagram of calcium carbonate with $100 \mathrm{ppm}$ HPAM added, and the result shows that a part of calcium carbonate is aragonite crystal form. Fig. 4 is the XRD dia-

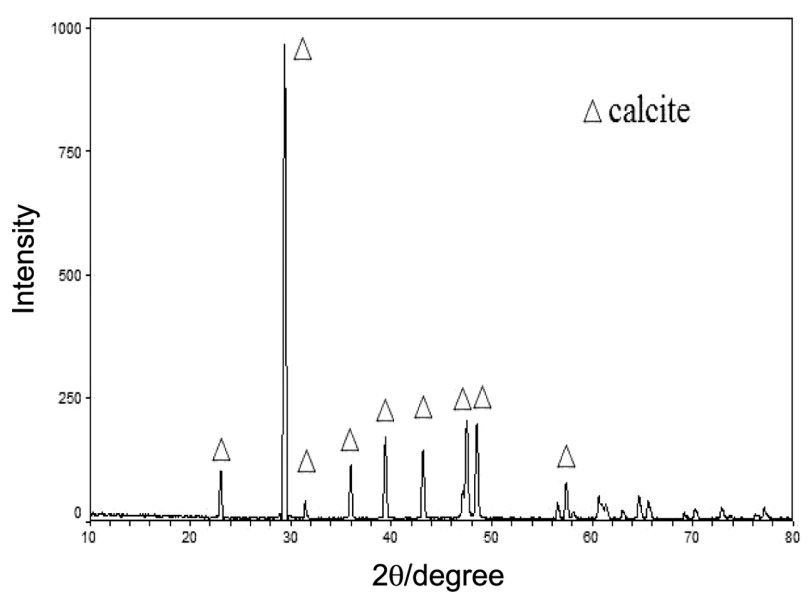

Figure 2. XRD diagram of calcium carbonate without HPAM. 


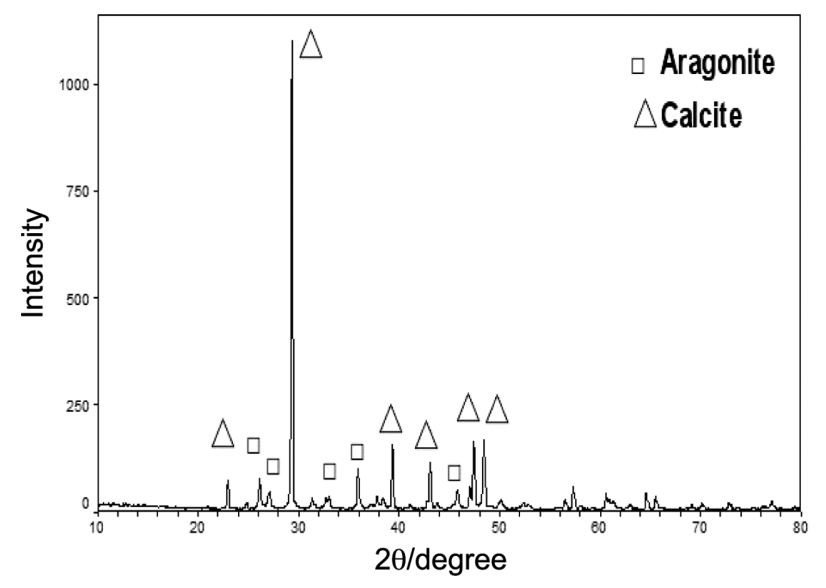

Figure 3. XRD diagram of calcium carbonate with 100 ppm HPAM added.

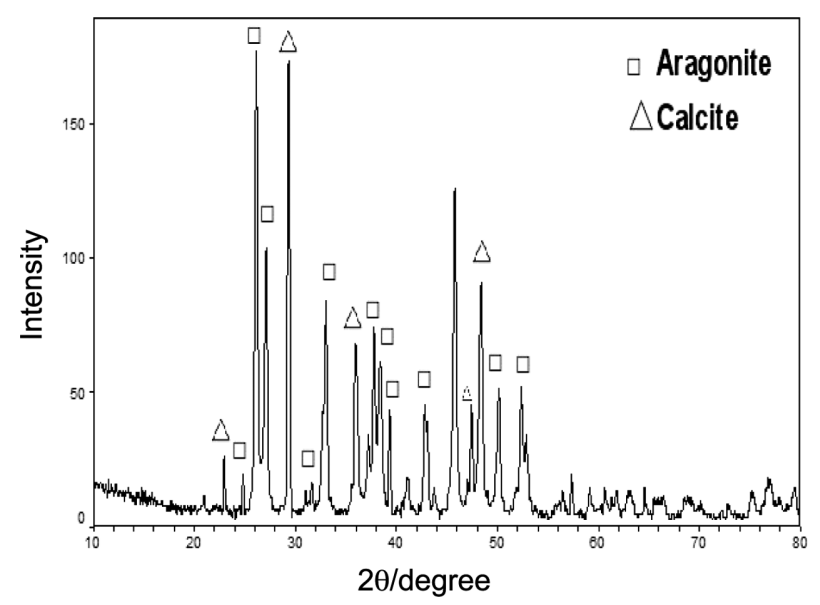

Figure 4. XRD diagram of calcium carbonate with 200 ppm HPAM added.

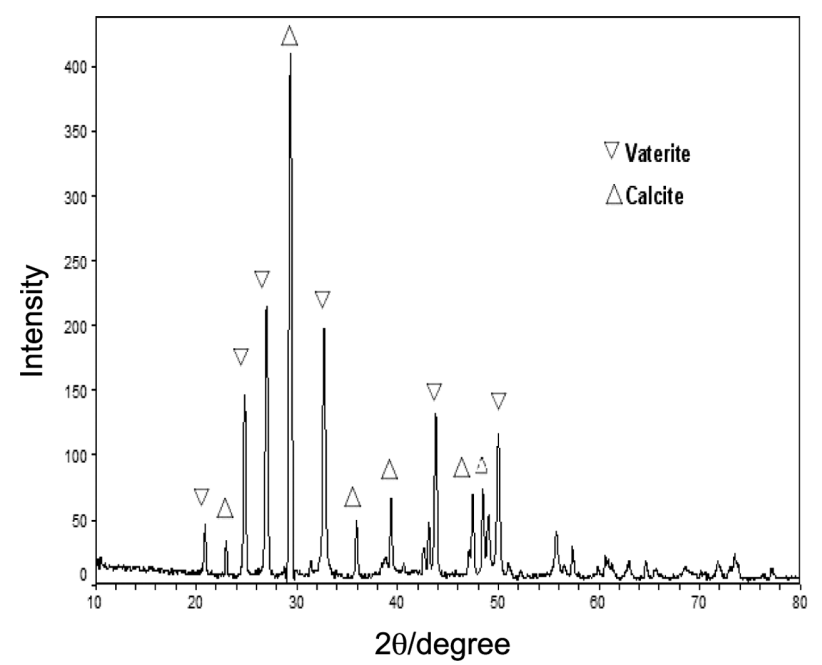

Figure 5. XRD diagram of calcium carbonate with $300 \mathrm{ppm}$ HPAM added. gram of calcium carbonate with 200 ppm HPAM added. It can be seen that the reaction system polymorphs are mainly aragonite. Fig. 5 is the XRD diagram of calcium carbonate with $300 \mathrm{ppm}$ HPAM added. It indicated that the polymorphs of calcium carbonate are mainly calcite and the spherical vaterite. It can be known from the analyses of XRD that the addition of HPAM affects the growth and formation of calcium carbonate polymorphs to some extent so that calcium carbonate polymorphs have a tendency to transform to metastable crystal forms.

\section{FI-IR Analysis}

The IR spectra lines from down to up in Fig. 6 are corresponding to the four samples described by Fig. 2 to Fig. 5 . It can be seen from Fig. 6 that the calcium carbonate without HPAM has two absorption peaks respectively at 876 $\mathrm{cm}^{-1}$ and $712 \mathrm{~cm}^{-1}$ ranging from $900 \mathrm{~cm}^{-1}$ to $600 \mathrm{~cm}^{-1}$, and the $712 \mathrm{~cm}^{-1}$ is the absorption peak of calcite; however, the IR spectrum of calcium carbonate generated with 100 ppm HPAM added has both the absorption peak of calcite at $712 \mathrm{~cm}^{-1}$ and the absorption peak of aragonite at $675 \mathrm{~cm}^{-1}$; the IR spectrum of calcium carbonate generated with 200 ppm HPAM added has the absorption peak of aragonite at $675 \mathrm{~cm}^{-1}$, and the intensity of this peak is much stronger than that of calcium carbonate peak with HPAM added whose molecular weight is 20 million; the IR spectrum of $\mathrm{CaCO}_{3}$ generated with 300 ppm HPAM added has the absorption peak of vaterite at $746 \mathrm{~cm}^{-1}$, but its intensity is much lower than that of calcite peak. It indicated that HPAM can cause the change of calcium carbonate polymorphs. It can be known that the HPAM has more inhibition on calcite than on aragonite and vaterite according to the analyses of the results of XRD and IR. It can be also indicated that calcium carbonate is more likely to

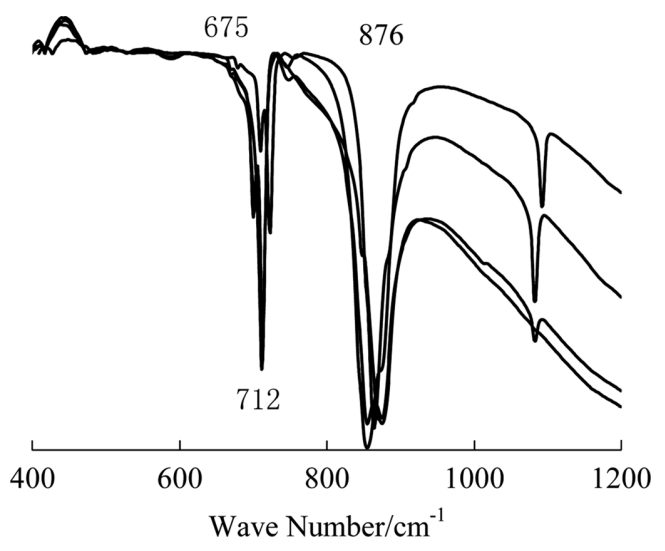

Figure 6. IR spectra diagram of calcium carbonate under different conditions. 
exist in the forms of vaterite and aragonite with the presence of HPAM.

\section{Scanning Electron Microscopy}

Calcium carbonate crystallizes in the forms of three different anhydrous polymorphs, and their stability is in the order of vaterite $<$ aragonite $<$ calcite. The common morphology of calcite is hexagonal prism or rhombohedron, and often called by cube and fusiform crystal. The shape of aragonite single crystal mainly includes needle-like, leaflike and massiveness. And the most common form is needle-like crystals. The common shape of vaterite is globular. On the basis of crystal morphologies observed by SEM, the crystal form of calcium carbonate can be determined.

Without HPAM added (Fig. 7), calcium carbonate particles exist mainly in form of hexagonal prism, so the crystal of calcium carbonate is mainly calcite. With HPAM added, the morphology of calcium carbonate changes, and deforming hexagonal prism, deforming cube, square piece, spindle shape, rod shape, disc shape, spherical shape, thin slice shape, flower shape and other forms of particles appear. The influence of HPAM on the morphology of calcium carbonate shows the following laws:

(1) Hexagonal columnar crystals become blunt, and the edges of crystals are uneven or the sides of the crystals become uneven (see Fig. 8 and Fig. 9). The morphologies are very similar to the forms of calcite single crystals, when HPAM has a little influence on the morphology of calcium carbonate scale.

(2) With the higher concentration of HPAM added, spherical shape scale appears. Spherical shape scale is clearly shown in Fig. 10. The morphology of the above scale has completely changed when compared with that of crystals

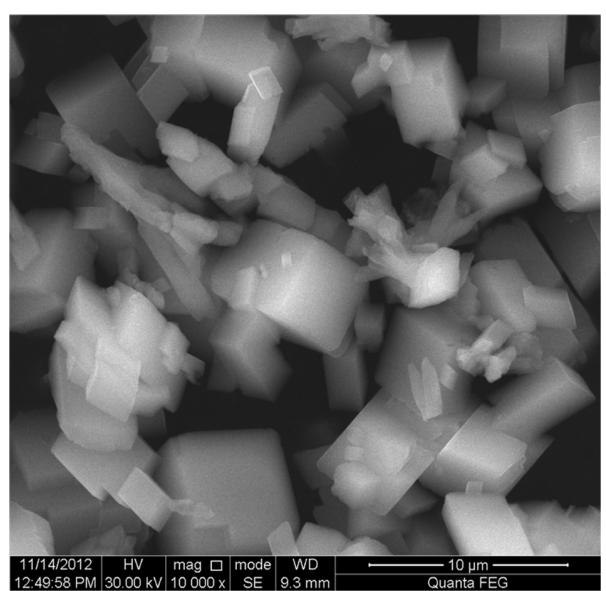

Figure 7. SEM image of calcium carbonate without HPAM.

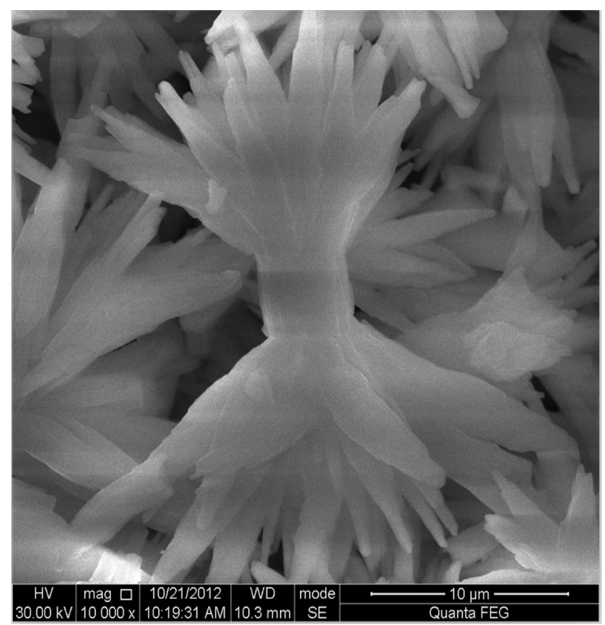

Figure 8. SEM image of calcium carbonate with 100 ppm HPAM added.

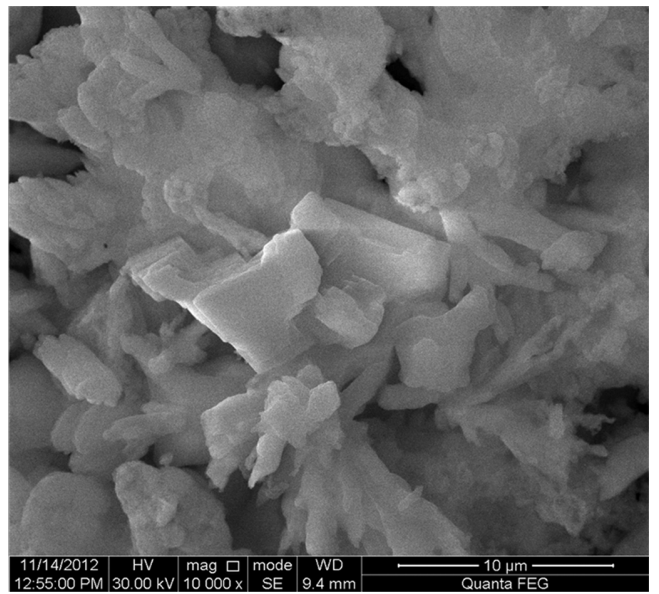

Figure 9. SEM image of calcium carbonate with 200 ppm HPAM added.

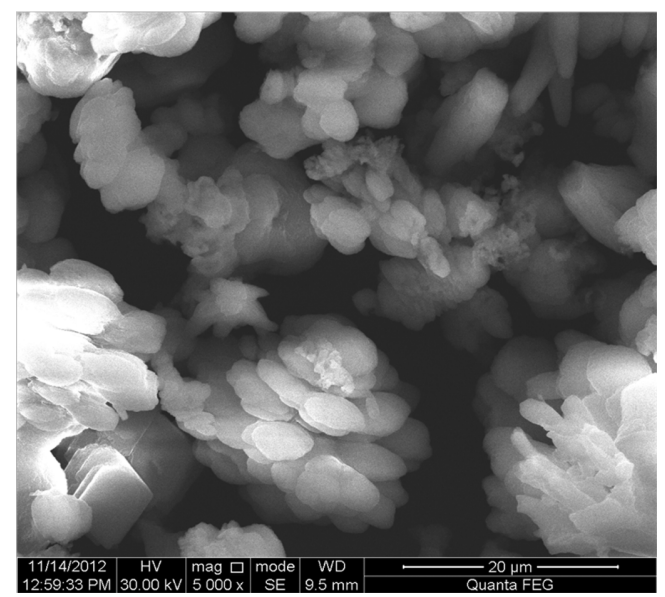

Figure 10. SEM image of calcium carbonate with 300 ppm HPAM added.

without HPAM added, so HPAM has much effect on the growth habit of scale in this condition. 


\section{Intrinsic Factor Analysis of Crystal Type Change}

It is generally thought that when the organic matter interacts selectively with crystal surface network in some direction by molecular recognition, its growth position will be hindered so that crystal growth rate in the direction perpendicular to this surface in relative to that of other direction surface network will be greatly reduced or even stop growing, thus this surface network is relatively stable and reflected in the final form. Under the action and regulation of HPAM, the spherical $\mathrm{CaCO}_{3}$ crystal is formed, and its reasons are probably because the stereochemistry conformational change of polymer in the aqueous solution induces a special morphology nucleation and growth of $\mathrm{CaCO}_{3}$ crystal. The experimental results show that with an increase in the amount of HPAM, calcium carbonate has a growth trendency to convert to globular shape from hexagonal prism. The reasons to lead to the change of morphology may be because carboxyl groups in polyacrylamide molecule and $\mathrm{Ca}^{2+}$ in solution form chelates by coordination bond, and then the chelates are adsorbed on the calcium hydroxide surfaces of solid-liquid interfaces so as to change the formation rate of calcium carbonate crystal nucleus.

\section{CONCLUSIONS}

(1) HPAM affected the crystallization process of $\mathrm{CaCO}_{3}$, so the metastable vaterite type of $\mathrm{CaCO}_{3}$ crystal was obtained which is difficult to exist in the water. The main morphology of $\mathrm{CaCO}_{3}$ crystal converts to metastable aragonite and vaterite from steady state calcite.

(2) With the higher concentration of HPAM, it has the greater effect on the crystal form of calcium carbonate. HPAM slows down the transformation from aragonite and vaterite to calcite. HPAM can control the crystallization behaviors of calcium carbonate scale. With the high concentrate of HPAM added, spherical scale is produced.

(3) The reasons to lead to the change of morphology may be because carboxyl groups in polyacrylamide molecule and $\mathrm{Ca}^{2+}$ in solution form chelates by coordination bond, and then the chelates are adsorbed on the calcium hydroxide surfaces of solid-liquid interfaces so as to change the formation rate of calcium carbonate crystal nucleus.

(4) The research provides a reliable basis for the mechanism research of the scaling problem in the oil extraction process of ASP flooding and the adoption of scale inhibition and scale inhibitor.

Acknowledgments. The research is financially supported by Scientific Research Fund of Heilongjiang Provincial
Education Department (No.12521047). And the publication cost of this paper was supported by the Korean Chemical Society.

\section{REFERENCES}

1. Sorbie, K. S.; Mackay, E. J. Pet. Sci. Eng. 2000, 27, 85106.

2. Crabtree, M.; Eslinger, D.; Fletcher, P.; Johnson, A.; King, G. Oilfield Review 1999, 30-45.

3. Todd, A. C.; Yuan, M. D. SPE. 1990, 5, 279-285.

4. Peyvandi, K.; Haghtalab, A.; Omidkhah, M. R. J. Cryst. Growth 2012, 354, 109-118.

5. Smith, B. R. Desalination 1967, 3, 263.

6. Hasson, D.; Bramson, D.; Limoni-Relis, B.; Semiat, R. Desalination 1997, 108, 67.

7. Hasson, D.; Semiat, R.; Bramson, D.; Bush, M.; LimoniRelis, B. Desalination 1998, 118, 285.

8. Ketrane, R.; Saidani, B.; Gil, O.; Leleyter, L.; Baraud, F. Desalination 2009, 249, 1397-1404.

9. Shakkthivel, P.; Sathiyamoorthi, R.; Vasudevan, T. Desalination 2004, 164, 111-123.

10. Gill, S. Desalination 1999, 124, 43-50.

11. Plummer, L. N.; Busenberg, E. Geochim. Cosmochim. Acta. 1982, 46, 1011-1040.

12. Andreassen, J. P. J. Cryst. Growth 2005, 274, 256-264.

13. Manoli, F.; Dalas, E. J. Cryst. Growth 2000, 217, 416-421.

14. Wang, C.; Li, S. P.; Li, T. D. Desalination 2009, 249, 1-4.

15. Ghizellaoui, S.; Lédion, J.; Ghizellaoui, S.; Chibani, A. Desalination. 2004, 166, 315-327.

16. Kırboga, S.; Öne, M. Colloid Surf., B. 2012, 91, 18-25.

17. Naka, K.; Chujo, Y. C. R. Chimie 2003, 6, 1193.

18. Jada, A.; Ait A. R.; Jacquemet, C.; Suau, J. M.; Guerret, O. J. Cryst. Growth 2007, 306, 373.

19. Wada, N.; Kanamura, K.; Umegaki, T. J. Colloid Interface Sci. 2001, 233, 65.

20. Mao, Z. F.; Huang, J. H. J. Solid State Chem. 2007, 180, 453.

21. Hacke, S.; Mobius, D.; Lieu, V. T. Appl. Surf. Sci. 2005, 246, 362.

22. Wang, L. L.; Meng, Z. L.; Yu, Y. Y.; Meng, Q. W.; Chen, D. Z. Polymer 2008, 49, 1199.

23. Neville, A. Energy Fuels 2012, 26, 4158-4166.

24. Crabtree, M. Oilfield Rev. 1999, 30-45.

25. DeLeeuw, N. H.; Parker, S. C. J. Phys. Chem. B. 1998, 102, 2914.

26. Ukrainczyk, M.; Kontrec, J.; Ivancic, V. B.; Brecevic, L.; Kralj, D. Powder Technol. 2007, 171, 192.

27. Deng, S. B.; Yu, G.; Chen, Z. X.; Wu, D.; Xia, F. J.; Jiang, N. Colloid Surf., A. 2009, 332, 63-69.

28. Rivas, H.; Gutierrez, X.; Zirrit, J. L.; Anton, R. E. Colloid Surf., A. 1997, 305-329.

29. Luis, E. Z.; Nestor, V. Q.; Pintos, T. S.; Salager, J. L. J. Pet. Sci. Eng. 2005, 47, 197-208.

30. Gabrielli, C.; Maurin, G.; Poindessous, G.; Rosset, R. J. Cryst. Growth 1999, 200, 236-250. 